\title{
AN APPLICATION OF QUALITATIVE MARKETING STUDIES IN THE IDENTIFICATION OF THE CONSUMER DECISION-MAKING PROCESS. EFFECTS AND BENEFITS
}

\begin{abstract}
The goal of the article is to present the effects and benefits of qualitative marketing research using the In-Depth Interview (IDI) method to examine consumer decision-making when purchasing products. The process pre-sented in the article focuses on a specific group of products in the interior design industry that are gaining rapid traction around the world and in Poland. The article focuses on the effects and benefits of the author's original qualitative 2019 research using the IDI method among potential buyers. The measuring tools included an interview scenario with a medium degree of standardisation and a voice recorder. The results of the research study together with the analysis of secondary sources, i.e. specialist literature and industry reports aided in designing the marketing strategy for the company that is the producer of the abovementioned products and formed the basis for planned quantitative market research.
\end{abstract}

Keywords: consumer behaviour, the consumer decision-making process, qualitative marketing studies.

\section{INTRODUCTION}

The literature on the subject presents many definitions of qualitative marketing research. They draw attention to various aspects of the concept. Most authors focus on the essence and main purpose of this research. For instance, Shank (Shank, 2002) defines qualitative research as "a form of systematic empirical inquiry into meaning (researchers try to understand how others make sense of their experience)". Denzin and Lincoln (2000) claim that qualitative research involves an interpretive and naturalistic approach: "This means that qualitative researchers study things in their natural settings, attempting to make sense of, or to interpret, phenomena in terms of the meanings people bring to them " (Denzin \& Lincoln, 2000; after Ospin, 2004). According to A.M. Nikodemska-Wołowik qualitative marketing research is research whose main task is to explain the behavior of the subjects, most often individual consumers, to find out the reasons and motives for their behavior, to enable understanding and proper interpretation of this behavior (Nikodemska-Wołowik, 1999). Often, instead of definitions, specific qualitative research features that distinguish them from quantitative research are mentioned. For example, Everet and Louis (1981) clarify the assumptions that ground each by distinguishing two research stances: "an inquiry from the

\footnotetext{
${ }^{1}$ Hanna Hall, PhD, Department of Marketing, Rzeszow University of Technology, al. Powstańców Warszawy 12, 35-959 Rzeszów; e-mail: hhall@prz.edu.pl. ORCID: 0000-0003-0967-9569.
} 
outside", often implemented via quantitative studies and "an inquiry from the inside" via qualitative studies. These approaches differ in the degree of the researcher's immersion in terms of experiential engagement, direct contact with the subjects, and physical involvement in the setting (Ospina, 2004).

The authors also point out other differences between quantitative and qualitative research, not only regarding their essence but also the subject of the study, a sample size, methods of their selection, methods of data collection, possibilities of generalizing results into a population, ways of presenting results (Baabie, 2004; Maison, Noga-Bogomilski, 2007; Kaczmarek, Olejnik, Springer, 2013).

The presented essence of qualitative marketing research and the features that distinguish it from quantitative research determine the benefits and limitations resulting from the implementation of these studies. The main benefit is difficult or impossible to achieve with the use of quantitative research, a thorough understanding of the way of thinking, conditions and specifics of the behavior of research entities, allowing the company to adapt its business, including its marketing strategy to identified needs, expectations, preferences, etc. The main limitation concerns the inability to make market decisions only on the basis of information derived from these studies. This is due to:

- small research samples on which qualitative research is carried out,

- the nature of the acquired information of a qualitative (usually verbal) nature, which, together with the previous feature, makes it impossible to generalize their results to a population,

- subjectivity of the researcher's interpretation of the test results,

- the possibility of respondents not telling the truth.

Therefore, qualitative research should be the basis for further, more objective and quantitative research carried out on large samples. It should be emphasized here that it is necessary to precede both of the above types of primary research, necessary multi-area secondary research based on data on the external and internal environment of the company.

Qualitative marketing research methods include primarily in-depth group interviews, indepth individual interviews, participant observations, ethnographic research, and other supportive techniques, such as projection techniques (Nikodemska-Wołowik, 1999; Maison, Noga-Bogomilski, 2007; Kaczmarek, Olejnik, Springer, 2013). For the purposes of this article, one of the types of IDI interviews was used. It is a semi-structured interview (with a set pattern of thematic threads but giving the researcher a lot of freedom, including related to the modification of the data collection process, e.g. asking additional questions explaining specific issues), which due to the opportunity to learn in depth about the conditions and specific behavior of respondents in the purchasing process was considered the most appropriate way of obtaining information. The research conducted focused on key elements of the rational decision-making process of the EKB (the name comes from the names of the authors Engel, Kollat, Blackwell, 1968; Stasiuk, Maison, 2014), assuming that in the case of interior design products this process will have such a rational nature (details related to the abovementioned elements can be found in the next part of the article: "Research assumptions").

The interior design industry, which includes the products to which the purchasing process relates, has been developing intensively both globally and in Europe ("The Retail Market...", 2019; "Global Furniture...”, 2019). The Polish home furnishings and furniture market is also growing rapidly (by 2022, its value is forecast at over USD 1 billion; currently 
it is valued at USD 600 million) ("Furniture \& Homeware", 2019). This increase is associated with the ongoing "housing boom" (which is conducive to, among others, low interest rates, which affect the growth of investment in real estate) as well as to the better condition of households and the growing tendency to carry out renovations.

The Polish home furnishings market, according to the analysis of secondary sources, is currently characterized by two characteristic changes. They concern: the growing (although still small compared to other countries) share of e-commerce in the sale of products of the industry being analyzed (in Poland e-shopping for home furnishings are still not very popular; it is estimated that only $2 \%$ buys this type of products only on the Internet, while in the world it is $21 \%$ ("Top Furniture Customer...", 2019); there are definitely more buyers in Poland who buy them both in stationary stores and online $-37 \%$ ) and new trends in the behavior of buyers of the abovementioned products. The decisive purchasing process of consumers related to the purchase of home furnishings begins with seeking inspiration) ("E-consumers", 2019), whose source is the Internet (especially blogs related to design, interior design portals, online stores offering interior design; among social networking consumers seeking home furnishings most often use Instagram as a social networking site focused on visual message) ("3 challenges in the furniture industry...", 2019). Characteristic for home furnishers is the "ROPO Effect" (Research Online, Purchase Offline) ("Perspectives and Trends...”, 2019) and webrooming (as opposed to showrooming, which means treating retail outlets as an exhibition gallery and a source of information when shopping online .) that is, as mentioned, searching for inspiration and information about specific products on the Internet and their purchase in stationary stores (" 3 challenges of the furniture industry...", 2019).

The further part of the article is devoted to a detailed analysis of the elements of the purchasing process of a specific group of interior design products based on the author's field research.

\section{RESEARCH METHODOLOGY}

The aim of the RESEARCH was to identify key elements of the purchasing process of individual buyers associated with products from the interior design industry used for wall finishing. Particular attention was focused on the criteria for choosing and preferring the abovementioned products, key sources of information in the purchase process, preferences and the process of choosing places to make purchases (it should be emphasized that the last of these elements is currently of particular importance for the functioning of companies in the analyzed industry).

The research problem consisted of the following questions:

1. What type of wall finish do respondents prefer?

2. What are the criteria for choosing the preferred wall finish?

3. What brands of wall finishing products do the respondents know about?

4. What sources of information (formal and informal) ${ }^{2}$ is used by respondents when seeking information on wall finishing?

5. What sources are a priority for them, taking into account the final decision?

\footnotetext{
${ }^{2}$ Formal communications are informative and promotional communications broadcast by producers and/or sellers, while informal ones are consumers expressing their opinions in person, on social networks, internet forums, etc.
} 
6. In what kind of sales outlets (traditional or online) do respondents most often buy the analyzed products?

7. What is the process of choosing the place of purchase (process identification: ROPO, reverse ROPO (Research Offline, Purchase Online) or ROTOPO (Research Online, Test Offline, Purchase Online)?

8. What is the hierarchy of factors determining the choice of a specific place to make a purchase (traditional or online)?

9. What is the spontaneous and supported awareness of DIY stores and Top of Mind ${ }^{3}$ (Aaker, 1992; Esch, 2007; Dabija, Abrudan, 2011).

10. Which of the stores respondents consider the best and for what reasons?

The research used to achieve the research objective was of a qualitative nature. The InDeph Interview was used as the research method, enabling detailed and completely free responses not suggested by the interviewer research questions.

The subjective scope includes persons being or planning to arrange their new place of residence (flats in a block of flats, terraced houses or detached houses) and/or being undergoing or planning renovation.

The respondents who took part in the survey were residents of the Podkarpackie, Małopolskie and the Śląskie voivodeships.

The time range of the survey was from June 20 to July 20, 2019. The sample for research was selected using the targeted selection method (the respondent had to meet the conditions specified in the subjective scope). For this purpose, the snowball technique was used, according to which respondents having the characteristics specified by the researcher are selected to be the sample, while being informants pointing to the researcher subsequent respondents with similar characteristics (Churchill, 2002). The sample size consisted of 20 people (12 women and 8 men, aged 35-70). One interview lasted from 40 minutes to 1.2 hours, depending on, among others on the degree of the respondent's involvement in the purchasing process.

The measurement tool applied in the study was an interview scenario with a medium degree of standardization. This choice of scenario type was associated with the possibility of obtaining completely free statements thanks to it, however, for specific, hierarchically arranged and asked questions to each respondent.

\section{RESEARCH RESULTS}

This part of the article presents the results of completed research together with selected quotes from interviews, in a special way emphasizing the merits of statements and having particular importance for creating the content of communication between the producer of analyzed products and the market. This significance results from the fact that customers rarely provide companies with their opinion on products, especially the positive one. They are more likely (though rarely) to express this negative, which results from the fact that the emotional response of a person to disappointment or dissatisfaction is stronger than to

\footnotetext{
${ }^{3}$ Spontaneous awareness is a percentage value expressing what part of the study group gives the product brand without the help of the interviewer; aided awareness is a percentage value expressing what part of the study group declares brand awareness after being read by the interviewer; TOM awareness (Top of Mind) is a percentage value expressing what part of the surveyed group mentions a given brand first (this is the first brand that comes to their minds).
} 
a positive experience, it is also a stronger emotion than satisfaction, it appears faster and lasts longer than satisfaction ( Giese, Cote, 2000; Jeong, Lee, 2014).

As the analysis of the answer to the first question regarding the merits of the study, referring to the preferred form of interior finishing, all respondents prefer painting the walls, but some of the respondents (10 people) also use additional decorations such as wallpaper, structural plaster, decorative brick.

The reasons for preferring paints as a wall finishing product include:

- easy to clean (this factor was mentioned by almost all respondents and almost always in the first place),

- aesthetics, with particular emphasis on the often emphasized rich colors (all women and none of the men paid attention to this aspect),

- quick and easy application (the criterion is expressed mainly by men who mostly paint their interiors themselves).

The respondents also mentioned the high availability and choice of paints, their low costs, tradition and preference for simplicity.

As one of the respondents said: "I prefer paints since they are simply easy to wash, which is especially important as I have children and animals". Interestingly, the role of pets in the selection of home furnishings has also appeared in other interviews. Another statement related to them read as follows: "I only use paints, because I have no choice, my cat has scratched the wallpaper, it would also destroy any other decoration on the walls. I am doomed to painting".

The benefits of using paints and their advantage over other ways of finishing the walls are expressed by the statement of one of the respondents: "I had experience with everything - paints, wallpapers, paneling. Paints are definitely the least troublesome". When asked to name the brands of producers producing any products for finishing and decorating the walls, the respondents only mentioned paint brands (Decoral, Śnieżka, Magnat, Dulux repeated several times). Not one producer of other products used by respondents was mentioned wallpaper, plaster or brick.

The next questions in the survey concerned sources of information used by respondents in the decision-making purchasing process related to wall finishing products. The main source of information for all respondents, which came as no surprise, was the Internet. It was mentioned first by all respondents.

The purpose of the next questions was to identify whether priority sources of information for respondents are formal or informal. From the respondents' opinions it follows that these are usually formal sources, which are pages with visualizations, treated by respondents as inspiration for decorating flats. Respondents usually found it difficult to determine exactly which pages they were on. The meaning of all statements was usually very similar to the following:

- "I just type in Google what I'm interested in, for example, wall paint «or» wall decoration "and watch everything pop up, one by one".

- "I am mainly interested in websites with comprehensive visualizations of rooms and flats. I received links to such websites from my interior designer".

Other formal sources mentioned by the respondents included specialized magazines related to interior design, such as "Cztery Kąty", "Dom i Wnętrze".

Respondents also used informal sources, asking for the opinions of their friends who have experience with interior furnishings and professionally involved in it. 
One of the key issues in the purchasing process is choosing the place to make the purchase. The results of research related to this issue turned out to be surprising, because all respondents clearly and without hesitation replied that all wall products have always bought only in traditional stores and do not take into account the purchase of Internet and. There are many reasons for this, according to the respondents' statements they include:

- an opportunity to see and touch the product (this answer was found in the statements of almost all respondents),

- seller consultancy,

- easy access,

- uncertainty associated with purchasing over the Internet,

- getting used to the given stationary point of sale.

Below are quotes reflecting the reasons and how to buy wall products in traditional stores:

- "Wall products have always been bought in normal stores, but I think all other home products are now available online".

- "I can search for information on the Internet, but if I want to buy paint or anything else for walls, I have to see it live, ask, compare prices".

- "I would be afraid to buy paint or other wall products online. If they had to be sent back, if something was wrong, it would be a big problem and cost".

Another question asked to the respondents was to explain their spontaneous, assisted awareness and Top of Mind in relation to DIY stores, which, according to the respondents' statements, are the most common place to buy the analyzed products.

The results of completed research in the area of awareness of DIY stores are presented in Table 1.

Table 1. Awareness of DIY stores brands

\begin{tabular}{|l|c|c|c|}
\hline \multicolumn{1}{|c|}{ Store brand } & Top of Mind (in \%) & $\begin{array}{c}\text { Spontaneous } \\
\text { awareness (in \%) }\end{array}$ & $\begin{array}{c}\text { Assisted awareness } \\
\text { (in \%) }\end{array}$ \\
\hline OBI & 40 & 60 & 100 \\
\hline Castorama & 20 & 70 & 100 \\
\hline Leroy Merlin & 10 & 80 & 100 \\
\hline Merkury Market & 10 & 30 & 100 \\
\hline Majster & 10 & 30 & 70 \\
\hline Mrówka & 10 & 20 & 80 \\
\hline Ptaktiker & 0 & 20 & 100 \\
\hline BricoMarche & 0 & 10 & 0 (unrequested) \\
\hline
\end{tabular}

Source: Author's own study based on IDI research.

In the lead when it comes to awareness of DIY stores, there were 3 stores: OBI, Castorama and Leroy Merlin. Market OBI appeared in the minds of respondents as the first among the largest number of people -8 people ( $40 \%$ of respondents). It is also the most frequently chosen market as a place to make a purchase. TOM's awareness turned out to be closely related to the place of purchase. 
The stores and reasons for preferences include:

- Castorama - due to the high level of customer service, a wide selection, and frequent promotions; according to one of the respondents: "There is great service. The service lady got interested in me, came up immediately when I came, she knew everything, showed me everything, she knew all the prices. I was shocked by this level of service".

- OBI - as in the case of Castorama, due to the good level of service and a wide range; example quote: "An employee came to me alone to ask what I was looking for. $100 \%$ someone saw me through the camera as I was running stupid in the store".

- Leroy Merlin - due to the largest opinion of the majority of respondents - the choice of products (the widest range).

According to the respondents' statements, they assess DIY stores mainly from the perspective of the level of service, as evidenced by the cited ways of explaining their preferences related to the place of purchase. Interest in the customer is particularly important in this respect - on the owner's initiative. The next determinant that determines the choice of a market is the width of the range.

\section{RESEARCH CONCLUSIONS}

The research allowed the identification of key elements of the decision-making process associated with the purchase of a specific group of products from the interior design industry for wall finishing. According to the research, the preferred form of wall finishing among respondents is painting. The main criteria for choosing this form are practical aspects, mainly related to maintaining cleanliness and speed of application (assembly and disassembly) and aesthetic values. An interesting criterion for choosing wall finishing products was also resistance to damage and dirt associated with having animals.

The research has shown a complete lack of awareness of the brands of manufacturers of wall finishing products (except for brands of paints identified with their producers).

The surprising result of the research seems to be buyers' use mainly of formal sources of information - websites with interior visualizations (the first phase of the information search process) and the seller's advice (the last, preceding the final decision, purchase phase). Informal sources for this type of product turned out to be of marginal significance for the surveyed buyers.

Traditional (stationary) sales outlets - DIY stores have proved to be the most popular place to buy the analyzed products. The advantage of traditional stores over online stores is due to the ability to see, view and compare products. The criteria for choosing a particular store as a place of purchase mainly included two criteria: quality of service, with particular emphasis on the employee's initiative in helping the customer, and the width of the range. The OBI, Castorama and Leroy Merlin supermarkets have priority in this respect in the minds of respondents.

The purchasing process of wall finishing products looked identical and closely reflected the ROPO process for all respondents. However, as the respondents say, this type of process does not apply to all home furnishings (as demonstrated by the results of secondary sources analysis). 


\section{SUMMARY}

Based on the research conducted, an insight was gained into the motivations, preferences and other determinants of behavior of buyers of a specific category of products, which enabled a number of benefits for their manufacturer, including planning:

- the content of promotional messages and company positioning based on product selection criteria important for buyers and free, unlimited scales, not suggested by the interviewer and thus more reliable statements of the respondents, in these messages it is planned to use words and expressions for greater impact of the message. used by respondents during research (among others presented in the above-mentioned quotes),

- modification of forms and means of communication with buyers based on identified key sources of information for buyers,

- modifications in the selection of product distribution channels, guided by recognized: respondents' preferences regarding places to make purchases, selection criteria and awareness of DIY stores,

- activities related to training of service employees in the distribution channels used, based on the respondents' experience in this respect,

- activities related to creating the brand awareness of the enterprise (producer of analyzed products), based on information about the complete lack of awareness of the brands of producers of wall finishing products.

Decisions on these aspects, as mentioned in the first part of the article, require obtaining more information implying the need for quantitative research on a much larger sample. The qualitative research allowed, in addition to the abovementioned the benefits also enabled planning the direction of these studies and taking the first modification actions, not related to financial risk and wrong decisions (e.g. preparation of necessary employee training in DIY stores).

\section{REFERENCES}

3 wyzwania branży mebli $i$ wyposażenia wnętrz w e-commerce [Access: 01.07.2019]. Access on the Internet: https://blog.arvato.pl/2018/11/21/3-wyzwania-branzy-mebli-i-wyposazeniewnetrz-w-e-commerce/

Aaker, D. (1992). Management des Markenwerts. Frankfurt-New York: Campus.

Baabie, E.. (2004). Badania spoteczne w praktyce. Warszawa: Wydawnictwo Naukowe PWN. Churchill, B. (2002). Badania marketingowe. Podstawy metodologiczne. Warszawa: Wydawnictwo Naukowe PWN.

Dabija, D.C., Abrudan I.N. (2011). Study On Retail Brand Awareness In Retail. "Annals of Faculty of Economics, University of Oradea, Faculty of Economics" Vol. 1(2) December.

Denzin, N., Lincoln, Y., eds. (2000). Handbook of Qualitative Research. London: Sage Publication Inc.

E-konsumenci (Consumer Journey Online), IAB Polska.

Engel, J.F., Kollat, D.T. and Blackwell, R.D. (1968). Consumer Behavior. Holt. New York: Rinehart \&Winston.

Esch, F.R. (2007). Strategie und Technik der Markenführung. Vahlen, München: Edi_ia a cincea. 
Evered, R., Louis, R. (1981). Alternative Perspectives in the Organizational Sciences. "Academy of Management Review" 6 (3).

Furniture \& Homeware [Access: 17.07.2019]. Access on the Internet: https://www.statista. com/outlook/255/146/furniture-homeware/poland

Giese, JL, Cote, JA. (2000). Defining consumer satisfaction. "Academy of Marketing Science Review” Retrieved July 30, 2013.

Global Furniture and Homewares E-Commerce, Coresight Research [Access: 16.07.2019]. Acccess on the Internet: https://www.fungglobalretailtech.com/research/global-furniture-andhomewares-e-commerce/

Jeong S.W., Lee K.H. (2014). Impact of evaluative criteria on satisfaction and dissatisfaction: identifying the role of knitwear involvement. Springer [Access: 05.09.2019]. Access on the Internet: https://link.springer.com/article/10.1186/s40691-014-0009-2

Kaczmarek, M., Olejnik, I., Springer, A. (2013). Badania jakościowe. Metody i zastosowania, Warszawa: CeDeWu.pl.

Maison, D., Noga-Bogomilski, A. (2007). Badania marketingowe. Od teorii do praktyki. Gdańsk: Gdańskie Wydawnictwo Psycholiczne,.

Nikodemska - Wołowik, A.M. (1999). Jakościowe badania marketingowe. Warszawa: PWE.

Ospina, S. (2004). Qualitative research [in:] Goethals, G.R., Sorenson, G.J., MacGregor Burns, J., eds., Encyclopedia of leadership. London: Sage.

Perspektywy i trendy internetowego rynku sprzedazy mebli [Access: 17.07.2019]. Access on the Internet: https://bluemedia.pl/pressroom/blog-fintech/perspektywy-i-trendy-internetowegorynku-sprzedazy-mebli-analiza

Shank, G. (2002). Qualitative Research. A Personal Skills Aproach. New Jersey: Merril Prentice Hall.

Stasiuk, A., Maison, D. (2014). Psychologia konsumenta. Warszawa: PWN.

The Retail Market for Home Furniture \& Bedding Industry in the US, IBISWorld [Access: 16.07.2019]. Access on the Internet: https://www.ibisworld.com/industry-trends/specializedmarket-research-reports/retail-market-reports/the-retail-market-for-home-furniture-bedding. html

Top Furniture Customer Acquisition Strategies to Boost Sales and Brand Loyalty [Access: 18.07.2019]. Access on the Internet: https://www.v12data.com/blog/top-furniture-customer-acquisition-strategies-to-boost-sales-and-brand-loyalty/.

DOI: $10.7862 /$ rz.2019.hss.37

The text was submitted to the editorial office: September 2019.

The text was accepted for publication: December 2019. 
